\title{
O HIDRÓXIDO DE CÁLCIO, AS PESQUISAS E O TEMPO
}

\section{Ronaldo Araújo Souza}

Doutor em Endodontia. Professor Adjunto de Odontologia da Escola Bahiana de Medicina e Saúde Pública. Salvador, Bahia, Brasil. http://orcid.org/0000-0003-3061-3898. rasouza@bahiana.edu.br

Apesar das aparências, a Endodontia vive um momento nada estimulante'.

Um momento em que um movimento, aparentemente sutil, induz os endodontistas a trilharem caminhos não muito consistentes.

Em nome da tecnologia fala-se sem os devidos cuidados da Endodontia feita com um único instrumento, em uma única hora, em uma única sessão.

Um movimento que alcança os alunos nas faculdades com o canto da sereia da simplificação, mas que na realidade se trata do simplismo do pensamento único.

O hidróxido de cálcio tem sido personagem importante nesse processo.

Cada vez mais são frequentes os relatos de colegas dizendo que há uma enorme pressão para "demonstrar" a inutilidade dessa substância.

Conversando com um especialista em Endodontia, uma colega the disse que ainda estava fazendo a especialização e que usava hidróxido de cálcio. Foi ○ suficiente.

"Ah, você ainda é do tempo do hidróxido de cálcio!"

E professou.

"Ora, se você alarga o canal, faz irrigação bem-feita, vedamento tridimensional com sistema de plastificação da guta percha..., para que ficar melando o canal com hidróxido de cálcio"?
E, sob a perspectiva da "endodontia moderna", achou que resplandecia.

Ela se limitou a ouvir a aula.

Não foi, como se poderia imaginar, o calar por consentir. Não é incomum que alguns se calem por perceber a inconsistência do interlocutor.

Se o controle de infecção é consensual para o êxito do tratamento endodôntico de casos com infecção do sistema de canais radiculares ${ }^{2}$, não parece sensata a proibição expressa ao uso de uma substância cuja ação antimicrobiana, entre outras, tem sido comprovada com inúmeros trabalhos ao longo dos anos.

Juntam-se aí dois aspectos de grande relevância quando o assunto é ciência; comprovação científica e o fator tempo.

Há alguém que duvide que ambos caminham de mãos dadas com o hidróxido de cálcio?

É grande a perplexidade diante desse momento em que o conhecimento adquirido é descartado em nome de algo com grande poder de sedução pelo absoluto descompromisso com o ensino, cujas consequências atingem cruel e indistintamente os mais jovens.

A ação antimicrobiana complementar do hidróxido de cálcio ao preparo do canal não constitui uma obrigatoriedade. Trata-se de alternativa de tratamento à disposição do endodontista ${ }^{3}$, devidamente sedimentada na pesquisa científica e consolidada pelo tempo. 
Obrigatoriedade que se observa quando ao aluno é dito que "aqui, tudo é em sessão única".

Por que essa postura se as informações disponibilizadas pela literatura estão longe de qualquer possibilidade de definição a favor de uma ou outra proposta de tratamento endodôntico, pelas evidentes limitações dos resultados de muitos artigos publicados?

Ao mesmo tempo, deseja-se o que? Que a literatura estabeleça diferenças marcantes a favor dessa ou daquela?

São os números e percentuais que nos ditam o que fazer?

Onde ficam a beleza e o encantamento do conhecimento empírico da área da saúde com a "não precisão" do saber que, ao forçar a imaginação, faz surgir o bom profissional?

Não seria erro grosseiro a definição de tratamentos baseada somente em valores numéricos?

Não conta o bom senso?

Estabelecendo-se como duas opções de tratamento, de que lado estaria ele?

Como chegar ao bom senso na área da saúde se não for pelos caminhos do discernimento clínico?

E como é possível chegar ao discernimento clínico através do simplismo do pensamento único? Afinal, pensamento único é não pensar.

Por outro lado, mesmo vistos sob essa ótica de alcance limitado, os resultados têm sido mais favoráveis à recomendação do uso do hidróxido de cálcio, com percentuais que variam de 10 a $20 \%$.

Não é a primeira vez que se deseja jogar essa substância na lata do lixo.

"Continuamos a acreditar que, apesar de haver fortes indícios de que o condicionamento ácido da polpa é uma alternativa viável e, algumas vezes, vantajoso em casos bem selecionados, ainda é cedo para abandonar totalmente o uso do hidróxido de cálcio nestas situações e recomendar a técnica como procedimento de rotina. Pelo contrário, acreditamos que para a maioria dos clínicos é prudente utilizar o hidróxido de cálcio"4.

Quem não lembra disso?

que levou os autores a essa reflexão depois de muitos anos de "combate" a essa substância?

A compreensão de que ao lado do hidróxido de cálcio estão a ciência e o tempo.

\section{REFERÊNCIAS}

1. Spångberg LSW. Are we doing enough? O Surg $O$ Med $O$ Pathol $O$ Radiol and Endod 2011;1 12(1):1-2.

2. Nair PNR. On the causes of persistent apical periodontitis: a review. Int Endod J 2006;39(4):249-281.

3. Souza RA, Silva-Sousa YTC, Colombo S, Lago M, Duarte $M A H$, Pécora JD. Healing of a tooth with an overinstrumented apex, extensive transportation and periapical lesion using a $5 \mathrm{~mm}$ calcium hydroxide apical plug: an 8-year follow-up report. Braz Dent J 2012;23(5):608-611.

4. Baratieri LN, Monteiro Junior S, Andrada Mauro AC, Vieira LCC, Cardoso AC. Odontologia Restauradora - Fundamentos e Possibilidades. 1. ed. São Paulo - SP: Livraria Santos 2001; $739 p$. 